\title{
Effectiveness of different obturation techniques in surpassing the ledge formed in simulated curved canals
}

\author{
Marilisa Carneiro Leão Gabardo', Wander José da Silva², Letícia Machado Gonçalves², \\ Marili Doro Andrade Deonízio³
}

\author{
${ }^{1}$ Area of Collective Health, School of Health and Biosciences, Pontifical Catholic University of Paraná, Curitiba, PR, Brazil \\ ${ }^{2}$ Department of Prosthodontics and Periodontology, Piracicaba Dental School, University of Campinas, Piracicaba, SP, Brazil \\ ${ }^{3}$ Area of Endodontics, Department of Dentistry, Federal University of Paraná, Curitiba, PR, Brazil
}

\begin{abstract}
Aim: To compare the effectiveness of different obturation techniques in surpassing the ledge formed in simulated curved root canals. Methods: Eighty acrylic-resin blocks with curved canals were instrumented with Gates-Glidden drills to simulate a ledge formation. Then, a K-File \#10 was used for trying to surpass the deviation, and the blocks that permitted surpassing were rejected. The remaining blocks were divided into 4 groups according to the obturation technique: lateral condensation, Tagger's Hybrid technique, Thermafil and System B. The blocks had their images digitalized using a scanner before and after the obturation procedures. The images were analyzed with Image Tool 3.0 software. Statistical analysis was performed by one-way ANOVA at a significant level of $5 \%$. Results: The System B resulted in the highest obturated area $(p<0.001)$. There were no significant differences between the Tagger's Hybrid technique and Thermafil system regarding the effectiveness in surpassing ledge $(p>0.05)$. The lateral condensation resulted in the worst ability in filling the ledge space $(p<0.001)$. Conclusions: Within the limitations of this study, it was possible to conclude that techniques using heat condensation or gutta-percha thermoplastification were more effective in surpassing the ledge formed in curved canals than the lateral condensation.
\end{abstract}

Keywords: endodontics, root canal therapy, root canal obturation, root canal filling materials.

\section{Introduction}

The major objective during an endodontic therapy is the cleaning, shaping

Received for publication: April 10, 2013 Accepted: June 25, 2013

Correspondence to: Marilisa Carneiro Leão Gabardo Rua Professor João Argemiro Loyola, 452, CEP: 80240-530, Seminário

Curitiba, PR, Brasi

Phone: +554132422304

E-mail: marilisagabardo@e-odonto.com and also filling the root canal properly ${ }^{1}$. However, the root canal system has a very complex anatomy that could difficult all steps of the treatment ${ }^{2}$.

During the root canal instrumentation, especially in curved canals, the maintenance of the original trajectory without causing deformations is a challenge ${ }^{3}$. Among the possible complications, an error characterized by a deviation that not reaches the periodontal ligament, is termed ledge formation or ledging. It is possible to detect when the file no longer achieves de curvature and brakes on a "deadlock"1,4-6.

Actually, there is a wide range of iatrogenic errors associated with ledge formation, but the inappropriate application of the technique prevails ${ }^{4}$. Of these, 
there are two major causes for the creation of ledged canals: inadequate extension of the access opening to allow straight access to the apical part of the root canal $^{5}$, and using a noncurved stainless steel instrument that is too large for a curved canal $^{7}$. In addition to the presence of root canal curvature, other contributory factors involved in ledge formation include tooth type, canal location, working length (WL), master apical file size, and clinician's level of experience in Endodontics ${ }^{6}$.

Once a root canal is ledged, the endodontic treatment becomes difficult to complete. Considering that the WL was not reached, the formation of a deviation implies an incomplete shaping and disinfection of root canal and, consequently, the obturation will also be compromised, which might lead to treatment failure ${ }^{4,8-10}$.

There are several techniques available to assist the negotiation and bypassing of a ledged canal, usually involving prebending the tip of files and/or using ultrasonic tips ${ }^{4,6}$. Thus, an alternative procedure in cases that the ledge was not surpassed and the WL was not recovered is the apical extrusion of the filling material with thermoplasticized techniques ${ }^{11}$.

Considering the high incidence of ledge formation in endodontic clinical practice ${ }^{5,12-14}$, and the limited information about apical extrusion of filling material as an alternative treatment in these cases, this study aimed to compare the effectiveness of different obturation techniques in surpassing the ledge formed in simulated curved root canals.

\section{Material and methods}

\section{Preparation of simulated canals with ledge}

A single operator performed all technical procedures for standardization purposes. Eighty transparent acrylic-resin blocks simulating root canals (P-Oclusal, São Paulo, Brazil) with $20^{\circ}$ curvature degree, $17 \mathrm{~mm}$ length and diameter and taper equivalent to a Flexofile \#15 (Dentsply Maillefer, Ballaigues, Switzerland) were used.

The ledge in the simulated canals was prepared with Gates-Glidden drills (Dentsply Maillefer) as follows: number 1 and 2 at $15 \mathrm{~mm}$, and number 3 at $13 \mathrm{~mm}$ (Figure 1A). The procedures were performed under irrigation with $1 \% \mathrm{NaOCl}$. Then, a K-File \#10 (Dentsply Maillefer) was used for trying to surpass the deviation by slightly prebending the file, with a slight rotation motion combined with a picking motion to help advance the instrument ${ }^{4}$. The blocks that allowed this passage were rejected (Figure 1B). The remaining blocks $(\mathrm{n}=64)$ were dried with paper points \#60 (Tanariman Indústria Ltda., Manacapuru, AM, Brazil) and covered with adhesive tape during the new trial to surpass the accident produced. This procedure was done to avoid seeing the file manipulation. Then, the blocks were divided into 4 groups containing 16 blocks each, according to the obturation technique: lateral condensation, Tagger's Hybrid technique, Thermafil (Tulsa Dental, Tulsa, OK, USA) and System B (SybronEndo, West Collins, CA, USA). AH-Plus sealer (Dentsply Maillefer) was used in all groups for obturation.

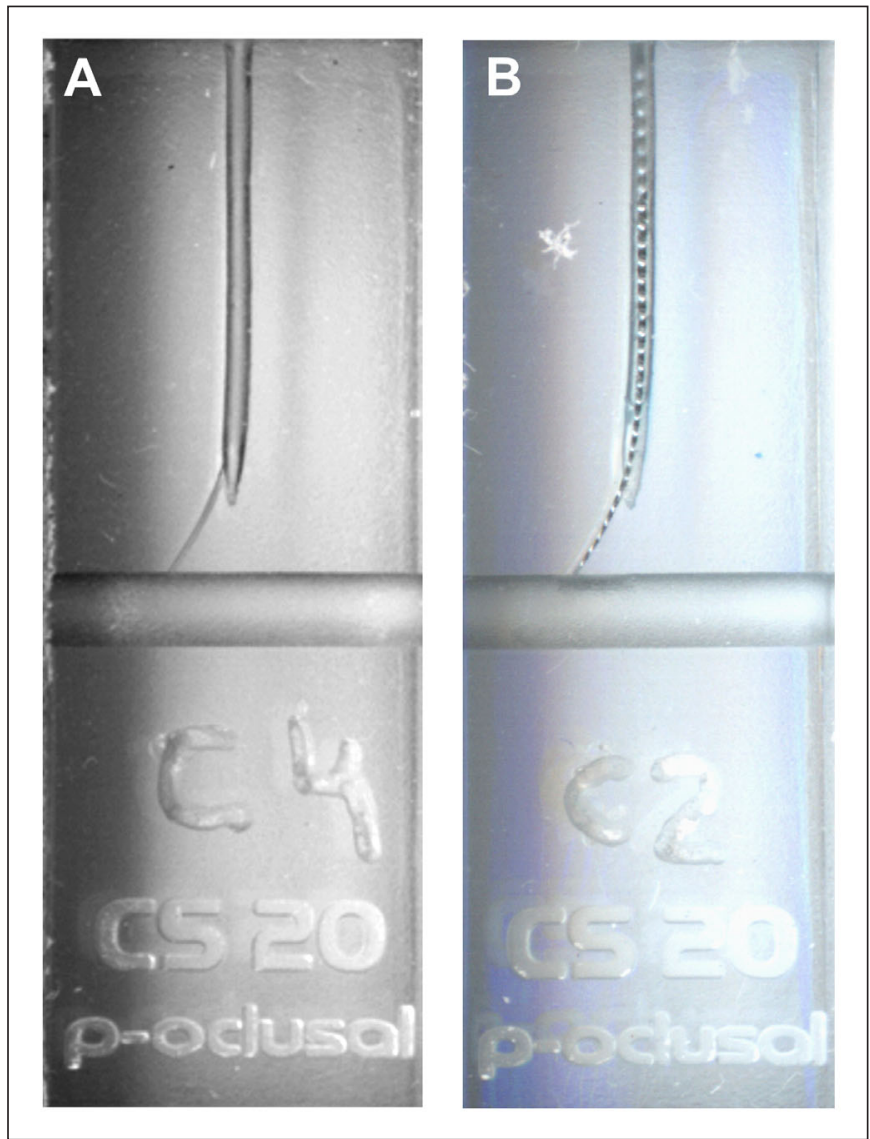

Fig. 1. (A) Simulated root canal with ledge in an acrylic-resin block. (B) K-File \#10 surpassing the ledge formed in the canal.

The sealer was prepared according with the manufacturer's instructions.

\section{Lateral condensation}

In this technique, a well-fitting master gutta-percha cone \#60 (Dentsply Maillefer) coated with sealer was taken up to the WL of $15 \mathrm{~mm}$. The master cone was left seated and the lateral condensation was performed using a finger spreader B (Dentsply Maillefer). This spreader was inserted with the sealer towards the canal walls and then counter-clock wisely removed to create room for the insertion of the accessory gutta-percha cones (Dentsply Maillefer) medium-fine(MF) (Dentsply Maillefer). This procedure was repeated until the insertion of new accessory cones was not possible. After the obturation completion, the excess of filling material was removed and cold vertical condensation was performed (Figure 2A).

\section{Tagger's Hybrid technique}

In this technique, the master cone was seated as described above. An initial lateral condensation was performed with the finger spreader $\mathrm{B}$, and one accessory gutta-percha cone was inserted. Next, a McSpadden compactor \#70 (Dentsply Maillefer) was coupled to a low-speed contra-angle handpiece and introduced passively into the root canal. The penetration of the compactor inside root canal was obtained 


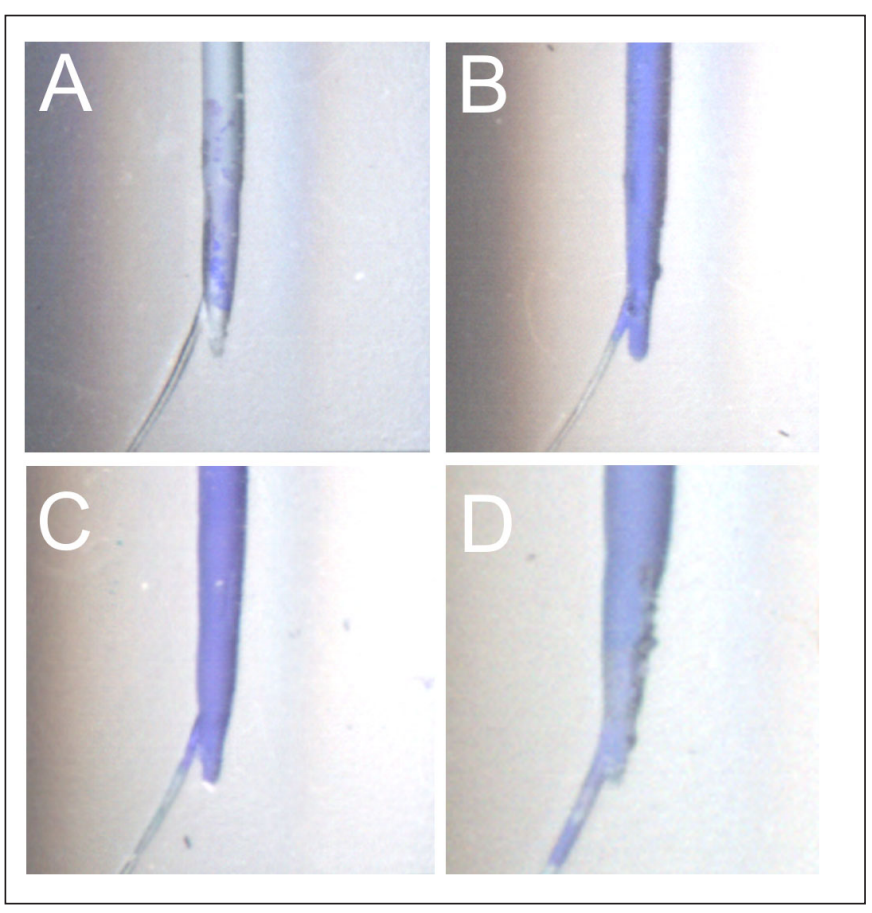

Fig. 2. Acrylic-resin blocks obturated with (A) Lateral condensation, (B) Tagger's Hybrid technique, (C) Thermafil and (D) System B.

with the aid of a rubber marker $1 \mathrm{~mm}$ short of the WL. With the McSpadden compactor inside the root canal, next to the gutta-percha cones, it was driven by forward-backward movements until reaching $\mathrm{WL}$, and then left at that point for about $1 \mathrm{~s}$. The compactor was removed from the root canal with the motor still operating maintaining gentle pressure on one side of the canal wall. Next, vertical condensation of the plasticized gutta-percha was performed with heat Paiva's condensers to obtain a better adaptation of the filling material (Figure 2B).

\section{Thermafil}

Initially, the appropriated size of gutta-percha plastic obturator was selected considering the diameter in the acrylicresin blocks. The size selected was \#45. Then, the prepared sealer was coated all over the root canal walls with the aid of a paper point \#60. The plastic obturator was heated in the Thermaprep Plus Oven (Tulsa Dental, Tulsa, Oklahoma, USA) and inserted into the canal at the WL of $15 \mathrm{~mm}$. The time required for obturation was selected according to the obturator size. Then, the external portion of the plastic obturator was removed with a round bur at high speed (Figure 2C).

\section{System B}

In this technique, the plugger $F$ was selected (SybronEndo, West Collins, California, USA). A gutta-percha cone \#60 (Dentsply Maillefer) was coated in sealer and then inserted into the canal. The plugger $\mathrm{F}$ was heated to approximately $200^{\circ} \mathrm{C}$ and introduced up to the site of deviation, being maintained there for approximately $10 \mathrm{~s}$. Next, the equipment was turned off and the plugger was kept in position with apical pressure. The equipment was turned on for just $1 \mathrm{~s}$ to remove the plugger.

The backfilling was done placing a fine-medium accessory gutta-percha cone (Dentsply Maillefer) coated with sealer into the empty backfill space. The System-B Heat Source, with the same plugger used before, was heated to $100^{\circ} \mathrm{C}$ and activated during about $0.5 \mathrm{~s}$. The plugger was firmly pushed and then held for $5 \mathrm{~s}$ with apical pressure maintained. The System-B plugger was rotated to break it loose. Next, with light back pressure, the plugger was rotated again to separate it from the condensed backfill cone. A second backfill cone was placed with sealer into the remaining backfill space left by the System-B plugger. So, the temperature was back up to $200^{\circ} \mathrm{C}$ and seared the cone off at the orifice level. Finally, the material in excess was also removed and condensed (Figure 2D).

\section{Digitalization and analysis of the images}

The acrylic-resin blocks had their images digitalized using a scanner (Genius HR7X, China) before and after the obturation procedure. The images analysis was performed using the Image Tool 3.0 software (UTHSCSA, San Antonio, TX, USA). The area observed before the obturation was measured in $\mathrm{mm}^{2}$ and denominated as initial area (IA). After performing the obturation technique the blocks were digitalized again and a new measurement was done. In this case, the material that was able to surpass the deviation was denominated as the final area (FA). The obturated area (OA) was calculated using the following equation: $\mathrm{OA}=\mathrm{IA}-\mathrm{FA}$ (Figure 3$)$.

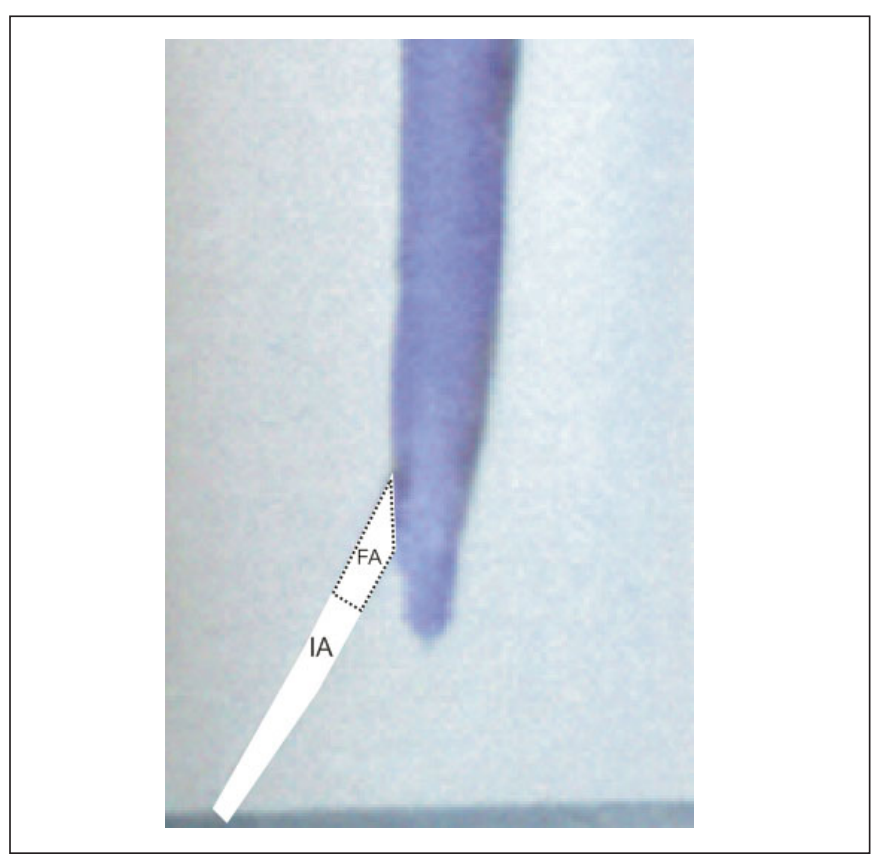

Fig. 3. Illustration of the initial area (IA) and final area (FA).

\section{Data analysis}

The data were analyzed using the SAS/LAB package (SAS Software, version 9.0; SAS Institute Inc., Cary, NC, USA) with the significant level set at 5\%. Differences between the obturation techniques were evaluated by one-way ANOVA. 


\section{Results}

The mean of the obturated areas obtained by the different techniques is shown in Figure 4. According to the results, the obturation using System B resulted in the highest obturated area $(p<0.001)$. There were no significant differences between the Tagger's Hybrid and Thermafil techniques regarding the efficacy in surpassing ledge $(p>0.05)$. The lateral condensation resulted in the worst ability in filling the ledge space $(p<0.001)$. It was not possible to identify the difference between gutta-percha and sealer when extrusion of the filling material occurred through the original trajectory.

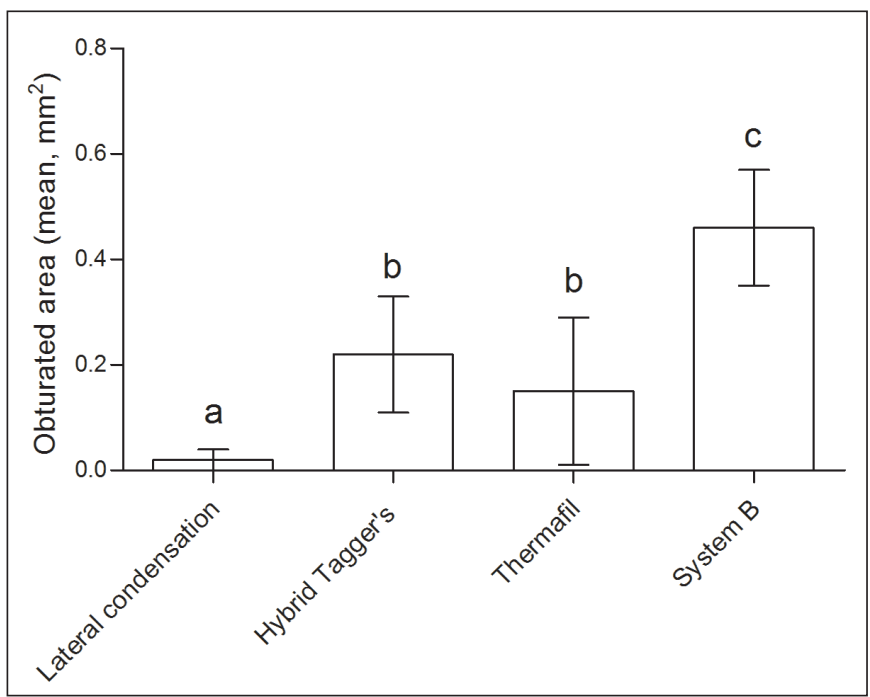

Fig. 4. Obturated areas according to the obturation techniques evaluated in the study. Different letters indicate statistically significant differences among the techniques.

\section{Discussion}

The maintenance of the original trajectory during the instrumentation of curved root canals remains as a challenge in endodontic clinical practice ${ }^{3,6}$. Actually, during instrumentation, accidents such as the ledge formation, have been described in the literature ${ }^{5,12}$, especially when the curvature of the root canal is accentuated ${ }^{13}$.

Prevention of these iatrogenic procedures is improved by training and experience, mainly with the application of techniques of cervical preflaring ${ }^{6,15-16}$. However, in case of its occurrence, handling must be done with an initial negotiation and bypassing the ledge and a combination of file's movements. If such movements fail, an area will not be reached and disinfected, representing a potential cause of poor prognosis ${ }^{4}$. Thus, the present study aimed to compare the effectiveness of different obturation techniques in surpassing ledge formed in simulated curved root canals, as an alternative to minimize unfavorable endodontic treatment outcomes.

Despite the limitation of in vitro studies, acrylic-resin blocks have been widely used in studies involving canal shaping and filling ${ }^{17-19}$, being confirmed as a reproducible model $^{20}$. In the present study, acrylic-resin blocks were used and having a single operator ensured standardization of all procedures. Also, a pilot-study confirmed that a deviation located at $15 \mathrm{~mm}$ was the length that permitted less surpassing the ledge.

Several techniques have been developed to achieve an adequate three-dimensional obturation of the instrumented root canal $^{1}$ and the gutta-percha-filled area tends to decrease at the apical level ${ }^{21}$. The most common technique is the lateral condensation of gutta-percha in combination with a sealer ${ }^{22-}$ ${ }^{24}$. However, in the present study, the lateral condensation showed the worst ability in surpassing the ledge formed in simulated curved canals. It is possible that the cold condensation of gutta-percha difficult the penetration of the filling material, especially nearby apical region ${ }^{25-26}$. Also, as the finger spreader penetrates until de ledge, it was not possible to introduce accessory cones in the ledge space ${ }^{23}$.

In addition to the classical cold lateral condensation, techniques have been introduced utilizing heat condensation of gutta-percha or thermoplasticized material in the canal. According to our results, the Tagger's hybrid technique, a heat condensation technique, and the Thermafil, a thermoplasticized one, resulted is similar obturated area. The Tagger's hybrid technique is known to be a technique able to produce a great overextension of filling material in curved and straight canals ${ }^{27}$. However, it seems that this technique is limited in surpassing ledges.

Actually, techniques in which thermoplastification is used, have a superior potential to extrude the material beyond the accident ${ }^{24,27-28}$. Also, a systematic review and meta-analysis confirmed that the root canal obturation by warm gutta-percha demonstrated a higher rate of overextension ${ }^{29}$. However, in our study, the Thermafil was less effective than the System B. The Thermafil system involves a heated alpha-phase guttapercha using a plastic carrier ${ }^{30}$. This system is claimed to be fast, easier and applicable in curved and narrow canals, the same characteristics proposed by the continuous wave of obturation technique, the System $\mathrm{B}^{31}$. Despite the advantages, under the tested conditions, it is possible that the plastic carrier used in Thermafil stopped at the level of the deviation, which did not allowed great material extrusion.

On the other hand, System B resulted in the highest obturated area, which could be explained by the depth capability of plugger penetration ${ }^{32}$. Furthermore, our results corroborate with those of previous investigations, indicating a direct correlation with the apical extrusion of the filling material ${ }^{33-34}$. Thus, this technique should be considered as a useful alternative in cases in which the return to the canal trajectory is not possible.

Overall, the heat condensation and thermoplasticized obturation were superior to the lateral condensation in surpassing the ledge formed in simulated curved canals. In these cases, the thermoplasticized obturation technique should be indicated for it higher ability of gutta-percha apical penetration. However, it is important to highlight that the Tagger's hybrid technique has advantages such as being fast and not requiring expensive devices, which could encourages 
its use by general dentists and endodontic specialists.

Within the limitations of this study, it was possible to conclude that techniques using thermoplasticized gutta-percha were more effective in surpassing ledge formed in curved canals than the lateral condensation.

\section{References}

1. Schafer E, Nelius B, Burklein S. A comparative evaluation of gutta-percha filled areas in curved root canals obturated with different techniques. Clin Oral Investig. 2012; 16: 225-30

2. Goldberg F, Artaza LP, De Silvio A. Effectiveness of different obturation techniques in the filling of simulated lateral canals. J Endod. 2001;27:362-4.

3. Burklein S, Benten S, Schafer E. Shaping ability of different single-file systems in severely curved root canals of extracted teeth. Int Endod J. 2013; 46: 590-7.

4. Jafarzadeh $\mathrm{H}, \mathrm{Abbott} P V$. Ledge formation: review of a great challenge in endodontics. J Endod. 2007; 33: 1155-62.

5. Kapalas A, Lambrianidis T. Factors associated with root canal ledging during instrumentation. Endod Dent Traumatol. 2000; 16: 229-31.

6. Terauchi Y. Correction of ledged canals with ultrasonic tips. Dent Today. 2008; 27: 140: 2-5.

7. Wilcox LR, Roskelley $C$, Sutton $T$. The relationship of root canal enlargement to finger-spreader induced vertical root fracture. J Endod. 1997; 23: 533-4.

8. Vire DE. Failure of endodontically treated teeth: classification and evaluation. J Endod. 1991; 17: 338-42.

9. Peters LB, Wesselink PR, Moorer WR. The fate and the role of bacteria left in root dentinal tubules. Int Endod J. 1995; 28: 95-9.

10. De Deus G, Murad CF, Reis CM, Gurgel-Filho E, Coutinho Filho T. Analysis of the sealing ability of different obturation techniques in ovalshaped canals: a study using a bacterial leakage model. Braz Oral Res. 2006; 20: 64-9.

11. Bernardineli N. Accidents and complicantions in instrumentation. In: Bramante CM, Berbert A, Bernardineli N, Moraes IG, editors. Accidents and complications in endodontic treatment - clinical solutions. São Paulo: Santos Publishing; 2003: p.50-106.

12. Eleftheriadis GI, Lambrianidis TP. Technical quality of root canal treatment and detection of iatrogenic errors in an undergraduate dental clinic. Int Endod J. 2005; 38: 725-34.

13. Greene KJ, Krell KV. Clinical factors associated with ledged canals in maxillary and mandibular molars. Oral Surg Oral Med Oral Pathol. 1990; 70: 490-7.

14. Santos SMC, Soares JA, César CAS, Brito-Júnior M, Moreira AN, Magalhães CS. Radiographic quality of root canal fillings performed in a postgraduate program in Endodontics. Braz Dent J. 2010;21: 315-21.

15. Goerig AC, Michelich RJ, Schultz HH. Instrumentation of root canals in molar using the step-down technique. J Endod. 1982; 8: 550-4.

16. Torabinejad M. Passive step-back technique. Oral Surg Oral Med Ora Pathol. 1994; 77: 398-401.

17. Burroughs JR, Bergeron BE, Roberts MD, Hagan JL, Himel VT. Shaping ability of three nickel-titanium endodontic file systems in simulated Sshaped root canals. J Endod. 2012; 38: 1618-21.

18. Goldberg M, Dahan S, Machtou P. Centering ability and influence of experience when using WaveOne single-file technique in simulated canals. Int J Dent. 2012; 2012: 206-321.

19. Hamze F, Honardar K, Nazarimoghadam K. Comparison of two canal preparation techniques using mtwo rotary instruments. Iran Endod J. 2011; 6: $150-4$.

20. Lam TV, Lewis DJ, Atkins DR, Macfarlane RH, Clarkson RM, Whitehead $M G$, et al. Changes in root canal morphology in simulated curved canals over-instrumented with a variety of stainless steel and nickel titanium files. Aust Dent J. 1999; 44: 12-9.
21. Marciano MA, Bramante CM, Duarte MA, Delgado RJ, Ordinola-Zapata $\mathrm{R}$, Garcia RB. Evaluation of single root canals filled using the lateral compaction, tagger's hybrid, microseal and guttaflow techniques. Braz Dent J. 2010; 21: 411-5.

22. Dummer PM. Comparison of undergraduate endodontic teaching programmes in the United Kingdom and in some dental schools in Europe and the United States. Int Endod J. 1991; 24: 169-77.

23. Dummer PM, Kelly T, Meghji A, Sheikh I, Vanitchai JT. An in vitro study of the quality of root fillings in teeth obturated by lateral condensation of gutta-percha or Thermafil obturators. Int Endod J. 1993; 26: 99-105.

24. Gulabivala K, Holt R, Long B. An in vitro comparison of thermoplasticised gutta-percha obturation techniques with cold lateral condensation. Endod Dent Traumatol. 1998; 14: 262-9.

25. Luccy CT, Weller RN, Kulild JC. An evaluation of the apical seal produced by lateral and warm lateral condensation techniques. J Endod. 1990; 16: 170-2.

26. Brosco VH, Bernardineli N, Moraes IG. "In vitro" evaluation of the apical sealing of root canals obturated with different techniques. J Appl Oral Sci. 2003; $11: 181-5$

27. Mann SR, McWalter GM. Evaluation of apical seal and placement control in straight and curved canals obturated by laterally condensed and thermoplasticized gutta-percha. J Endod. 1987; 13: 10-7.

28. Clinton K, Van Himel T. Comparison of a warm gutta-percha obturation technique and lateral condensation. J Endod. 2001; 27:692-5.

29. Peng L, Ye L, Tan H, Zhou X. Outcome of root canal obturation by warm gutta-percha versus cold lateral condensation: a meta-analysis. J Endod. 2007; 33: 106-9.

30. Beasley RT, Williamson AE, Justman BC, Qian F. Time required to remove guttacore, thermafil plus, and thermoplasticized gutta-percha from moderately curved root canals with protaper files. J Endod. 2013; 39: 125-8.

31. Buchanan LS. The continuous wave of obturation technique: 'centered' condensation of warm gutta-percha in 12 seconds. Dent Today. 1996; 15: 60-2, 64-7.

32. Zhang W, Suguro H, Kobayashi Y, Tsurumachi T, Ogiso B. Effect of canal taper and plugger size on warm gutta-percha obturation of lateral depressions. J Oral Sci. 2011; 53: 219-24.

33. Guess GM, Edwards KR, Yang ML, Iqbal MK, Kim S. Analysis of continuous-wave obturation using a single-cone and hybrid technique. $J$ Endod. 2003; 29: 509-12.

34. Jung IY, Lee SB, Kim ES, Lee CY, Lee SJ. Effect of different temperatures and penetration depths of a System B plugger in the filling of artificially created oval canals. Oral Surg Oral Med Oral Pathol Oral Radiol Endod. 2003; 96: 453-7. 